\title{
ПОДХОД К ОЦЕНКЕ ТРУДОВОГО КАПИТАЛА РАБОТНИКОВ В ОРГАНИЗАЦИИ
}

\author{
В. Я. Иванова \\ Российский государственный университет имени А. Н. Косыгина
}

Поступила в редакцию 2 декабря 2019 г.

\begin{abstract}
Аннотация: установленная на теоретическом уровне взаимосвязь между трудовым и человеческим капиталом позволила в рамках исследования влияния организационной культуры на процесс капитализации трудового потенциала работников в организации сформулировать определение терминологической единиць «трудовой капитал» и предложить подход к его оченке.
\end{abstract}

Ключевые слова: человеческий капитал, актуализация, трудовой капитал, капитализаичя, капитализация трудового потенцчиала, подход к оченке трудового капитала.

Annotation: the relationship between labor capital and human capital had been established at the theoretical level that allowed to formulate definition and suggest an assessment approach to terminology unit «labour capital» in the context of the influence of organizational culture on the process of capitalization of the labour potential of employees in the company.

Key words: human capital, actualization, labour capital, capitalization, labour capital capitalization, methods of labour capital assessment.

Обзор научной литературы, посвященной исследованиям нематериальных составляющих социально-экономических процессов, показал недостаточную изученность на теоретическом уровне сложного термина «трудовой капитал» (далее - ТК) и, как следствие, отсутствие методической базы, связанной с его оценкой.

В рамках исследования влияния организационной культуры на процесс капитализации трудового потенциала работников в организации проведен терминологический анализ, послуживший основой для определения простых терминов («человек», «труд», «потенциал», «ресурс», «капитал») и сложных («трудовой потенциал» и «человеческий капитал», «человеческий потенциал», «человеческий ресурс», «трудовой ресурс» и «трудовой капитал») [1, с. 61-70]. С помощью ГОСТ Р ИСО 704-2010 (ISO 704:2009) установлен вид отношений (рис. 1), возникающий между перечисленными терминологическими единицами [2, с. 211-218].

Изображенные на рис. 1 взаимосвязи позволяют на теоретическом уровне описать происходящие между рассматриваемыми терминологическими единицами процессы [1, с. 61-70].

В философских суждениях для толкования «осуществления внутренней цели того или иного существа [3, с. 317]» и «расточения того богатства возможностей, которым располагает индивид» [там

(С) Иванова В. Я., 2020 же, с. 94] используется категория «актуализация», с помощью которой возможно проведение качественного анализа [там же, с. 89], чьим объектом является человек. Исходя из этого, трансформация имеющихся средств и возможностей в реализуемые, происходящая в рамках совокупности социально-исторических действий [4, с. 101-110] (т. е. преобразование человеческого потенциала в человеческий капитал), представляет собой процесс, который можно определить термином «актуализация».

Существует множество проявлений человеческой деятельности, труд - одно из них [1, с. 61-70]. Часть актуализации, в ходе которой капитал обращается в стоимость посредством реализации целенаправленных предметно-преобразующих действий, т. е. «труда», можно описать путем обособления ряда сложных терминов - «трудовой потенциал», «трудовой ресурс» и «трудовой» капитал». Преобразование имеющихся средств и возможностей в реализуемые в ходе той части социальноисторических действий, которые относятся к определенным целенаправленным предметно-преобразующим, представляет собой «процесс капитализации трудового потенциала» (рис. 2) [2, c. 211-218; 4, с. 251-255].

Существующий между терминологическими единицами вид отношений $[1$, c. 61-70] позволяет на теоретическом уровне доказать, что процесс капитализации трудового потенциала является частью процесса актуализации человеческого по- 


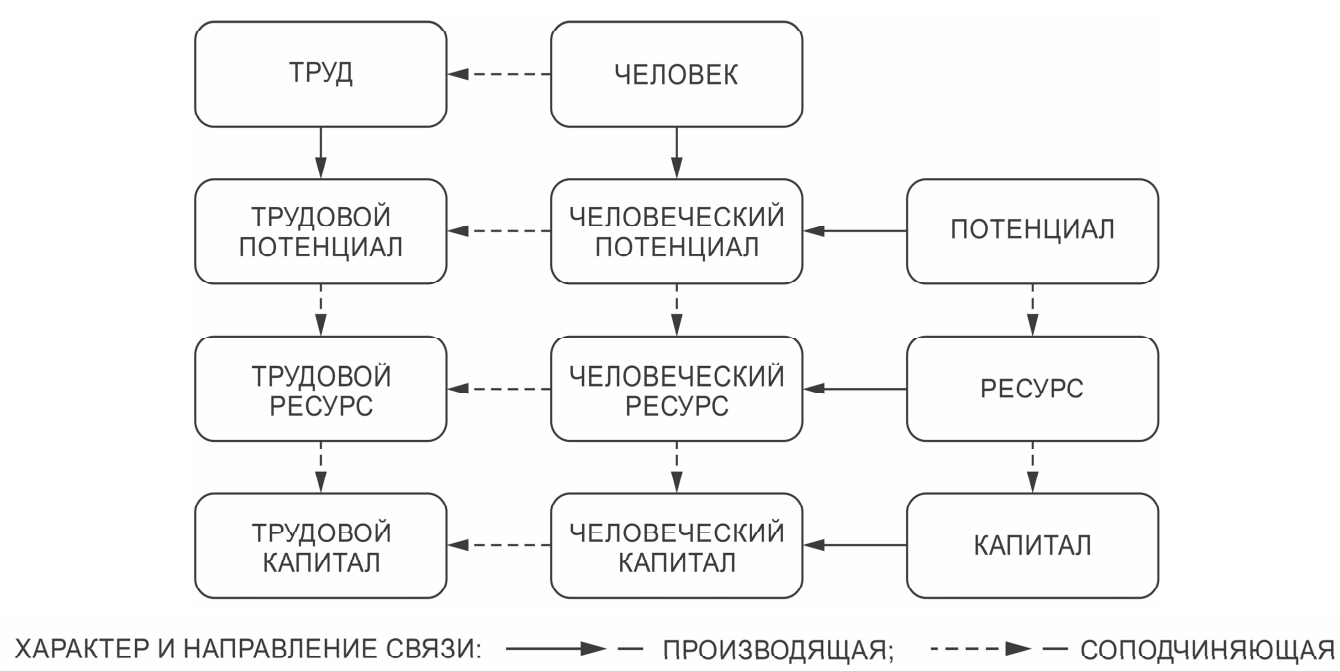

Puc. 1. Схема соподчинения простых и сложных терминов (составлена автором)

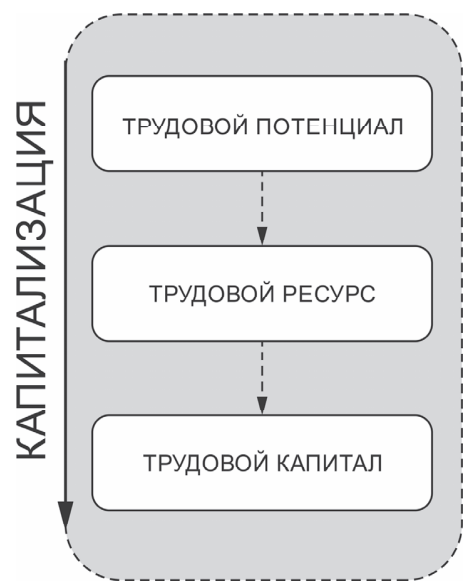

Puc. 2. Схема преобразования трудового потенциала в трудовой капитал (процесса капитализации трудового потенциала) (составлена автором)

тенциала, тогда как ТК представляет собой часть человеческого капитала (далее - ЧК), которая формируется в рамках трудовой деятельности. Исходя из этого, для разработки способа измерения ТК целесообразно обратиться к рассмотрению методик расчета ЧК.

История формирования и развития подходов к оценке ЧК отражена в работах зарубежных и отечественных ученых (В. Петти, А. Смита, Д. Рикардо, К. Маркса, Т. У. Шульца, Г. С. Беккера, Л. Дублина и А. Лотки, М. М. Критского, А. В. Корицкого, А. И. Добрынина, С. А. Дятловой, Р. И. Капелюшникова, В. С. Гойло и многих других).

Изучение методик расчета ЧК позволило выявить качественный (компонентный), количественный и интегральный подходы к его оценке, специфика применения которых представлена в таблице.

В зависимости от стоящих перед авторами задач разрабатывались и применялись различные варианты измерения ЧК. При формировании способа оценки ТК учтены сущность определения этого сложного термина $[1$, с. 61-70], возможность количественной интерпретации, универсальность применения для работников организации, участвующих в трудовой деятельности.

Особенности реализации качественного подхода к оценке ЧК отражены в работах Т. Г. Мясоедовой, Н. Л. Борщевой, К. П. Каменевой.

Для измерения ЧК Т. Г. Мясоедова применяет основы теории вероятности. Автор обособляет следующие элементы ЧК как вероятностной величины: природные способности, здоровье, знания, мотивацию и общую культуру. Перечисленные составляющие могут принимать значения от 0 до 1 и представляют собой независимые события [6, с. 29-37].

В работе Н. Л. Борщевой структура ЧК работника описана с помощью профессиональных, интеллектуальных и креативных уровней (показате- 
Подход к оценке трудового капитала работников в организацчии

Т а б л и ц а

Описание подходов к оценке человеческого капитала

\begin{tabular}{|c|c|c|}
\hline $\begin{array}{c}\text { Подход к оценке } \\
\text { человеческого капитала }\end{array}$ & Особенности применения & Использование авторами \\
\hline $\begin{array}{l}\text { Качественный } \\
\text { (компонентный) }\end{array}$ & $\begin{array}{l}\text { Выявление набора уровней или со- } \\
\text { ставляющих элементов, необходимых } \\
\text { для описания ЧК или его структуры } \\
\end{array}$ & $\begin{array}{c}\text { Т. Г. Мясоедова, Н. Л. Борщева, } \\
\text { К. П. Каменева и др. }\end{array}$ \\
\hline Количественный & $\begin{array}{l}\text { Применение финансово-экономиче- } \\
\text { ских (стоимостных и натуральных) } \\
\text { показателей для измерения ЧК }\end{array}$ & $\begin{array}{c}\text { У. Фарр, Т. Витстейн, Л. Дублин и А. Лотка, } \\
\text { Л. Туроу, Т. Шульц,И. Фишер, Г. Беккер, } \\
\text { М. Фридмен, М. И. Бухалков, Н. И. Пирожкова, } \\
\text { Я. Фитц-енц и др. }\end{array}$ \\
\hline Интегральный & $\begin{array}{l}\text { Совмещение качественных и коли- } \\
\text { чественных методов, необходимых } \\
\text { для объемного измерения ЧК в про- } \\
\text { странстве и времени }\end{array}$ & О.Н.Покусаев, Б. В. Корнейчук и др. \\
\hline
\end{tabular}

Источник: таблица составлена автором.

лей). Содержание уровней строится на экспертной оценке, учитывающей весовой коэффициент, определяющий важность определенного показателя. Для расчета ЧК организации автор использует среднеарифметическое значение индивидуальных профессиональных, интеллектуальных и креативных уровней сотрудников [7, с. 230-240].

В методике, предложенной К. П. Каменевой [8, с. 34], ЧК представляет собой сумму различных капиталов (капитал семьи, капитал здоровья, капитал образования, капитал профессионально-квалификационного опыта, капитал культуры). Каждый из элементов, составляющих ЧК, является обобщающей характеристикой, основанной на статистических данных социально значимых показателей региона.

В способах оценки ЧК Т. Г. Мясоедовой, Н. Л. Борщевой, К. П. Каменевой используется характеристики (здоровье, образование, профессионализм, способности и др.), которые Б. М. Генкин, Н. И. Шаталова и С. Г. Радько применяют для измерения трудового потенциала (далее - ТП) [9, с. 57-65]. Исходя из этого, можно сделать вывод о том, что авторы качественных методик сводят рассмотрение и описание ТП и ЧК к равенству, согласно которому ТП $=$ ЧК.

Кроме того, анализ качественных подходов к оценке ЧК позволил выявить отсутствие универсального набора реализуемых средств и возможностей, необходимых для описания ограниченного набора компонентов ЧК. Ряд характеристик, предлагаемых авторами для расчета ЧК относятся непосредственно к тем, которые реализуются в процессе определенной целенаправленной предметно-преобразующей деятельности (т. е. в ТК): профессиональный, интеллектуальный и креативный уровни ра- ботника [7, с. 230-240], капитал профессионально-квалификационного опыта [8, с. 33-37].

Особенности генезиса взглядов на количественную оценку ЧК отражены в трудах ряда авторов (таблица).

Концепция стоимости ЧК У. Фарра разработана на основе методики В. Петти. Стоимость ЧК рассчитывается как чистый дисконтированный доход от инвестиций в работника в определенный период времени [10, с. 58-59], т. е. как капитализированный будущий доход работника. Оценка ЧК, предлагаемая Т. Витстейном, применяется при страховании жизни человека [10, с. 61-62]. В расчете автора включена величина будущих доходов с учетом различных затрат (на потребление, включая образование), которые отражают в денежных единицах стоимость человека определенной профессии, вступившего в трудовую деятельность в конкретный момент времени. За основу измерения значения ЧК Л. Дублиным и А. Лоткой взяты расчеты, предложенные У. Фарром [10, с. 62-63; 11, с. 39-40]. Методика авторов представляет собой расчет капитализации (с использованием фактора времени) заработка индивидуума за вычетом затрат на содержание и позволяет рассчитать экономическую ценность человека для его семьи, самого себя и для общества. В работе Л. Туроу представлено производственное (стоимостное) выражение ЧК, где учитывается человеческое время [12, с. $163-$ 164]. Особенностью вычисления является определение вероятностных величин заработков и издержек. В формуле Т. Шульца [там же, с. 167-168] определяется объем ЧК, все составляющие которого включены в процесс производства и капитализируются в определенный период времени. Для расчета ЧК И. Фишер использует дисконтирование 
[там же, с. 193] (отношение величины будущего дохода к текущему с заданной процентной ставкой за определенное количество лет). Расчет стоимости ЧК, предлагаемый Г. Беккером [там же, с. 194], учитывает возраст, активную трудовую деятельность и заработную плату работника, т. е. раскрывает содержание трудовой части (ТК). Такой подход обеспечивает возможность сравнения величины ЧК работников одной возрастной категории. Методика М. Фридмена [там же, с. 195-196] позволяет измерить общую величину ЧК, в которую закладывается срок трудовой деятельности индивидуума (относящийся к ТК), доходность от имущества и заработок в единицу времени (год). В подходе М. И. Бухалкова [13, с. 112$]$ для измерения ЧК используется стоимостная оценка производственных показателей предприятия, в том числе основного, оборотного капитала предприятия и инвестиционных ресурсов. В основу величины ЧК отдельного работника предприятия Н. И. Пирожкова [14, с. 59-61] закладывает промежуток времени, за который реализуются квалификационные навыки сотрудника (с учетом его экономической значимости), т. е. происходит расчет ТК. Формула имеет денежную интерпретацию за счет оценки знаний, умений, навыков и опыта работников с помощью заработной плату. В расчетах Я. Фитц-енца [15, с. 53-69] используются характеристики, относящиеся к трудовой деятельности работников.

Изучение количественных методик измерения ЧК позволяет сделать заключение о применении авторами различных показателей, которые могут быть представлены в стоимостных, натуральных и временных единицах. Среди стоимостных методик оценки ЧК особого внимания заслуживает предложенный Л. Дублиным и А. Лоткой подход, основанный на расчете капитализации заработка, который можно практически применять как для определения величины ЧК, так и его компонентов. Данный вид расчета экономической значимости способностей человека к труду (или ТК) технически совершенен и пригоден для практического использования в реальной ситуации [11, с. 27-28].

Часть переменных, задействованных учеными при расчете ЧК, относятся к характеристикам ТК (период активной трудовой деятельности, часть заработной платы, приходящаяся на труд, основной и оборотный капитал предприятия, коэффициент квалифицированности всех работников предприятия и др.). Неотъемлемым параметром, используемым в количественных методиках оценки ЧК, является время.
Рассмотрение ТК как конечного этапа капитализации ТП (см. рис. 2) и той части ЧК, которая относится к трудовой деятельности [5, с. 211-218], позволяет сделать вывод о том, что для количественной оценки ТК целесообразно применять показатель, который будет отражать фактически затраченное время $\left(t_{3}\right)$ в рамках трудового процесса.

Некоторые исследователи, создавая возможность для всестороннего рассмотрения социально-экономической сущности ЧК, предприняли попытки совмещения качественного и количественного подходов к его оценке для получения интегральных характеристик. В методике О. Н. Покусаева $[16$, с. $138-156]$ качественная часть ЧК работника отражена в форме совокупности личностных компетенций, образования (профессиональное, дополнительное), повышения квалификации и получения опыта, а количественная характеристика выражена в периоде трудового стажа. Используемые автором параметры относится к той части, которая является ТК. Подход Б. В. Корнейчука $[17$, с. $67-68]$ предназначен для измерения ЧК региона (страны), где качественные составляющие выражены с помощью индексов образования и здоровья занятого населения, а количественный показатель представляет собой численность населения. В предлагаемой автором формуле не учтена часть населения, которая не занята в трудовой деятельности.

Обзор различных подходов (качественных, количественных и интегральных) к измерению ЧК позволяет сделать вывод о том, что в основу его расчета включены показатели, характеризующие ту его часть, которая относится к трудовой деятельности (т. е. ТК). С учетом особенностей проводимого исследования принято решение о возможности объединения качественных и количественных характеристик для разработки интегральной формулы оценки ТК, которая будет иметь следующий вид:

$$
\mathrm{TK}=t_{3} \cdot f\left(a_{1}, a_{2}, a_{3} \ldots a_{n}\right),
$$

где $a_{1}, a_{2}, a_{3} \ldots a_{n}-$ это характеристики реализуемых средств и возможностей в процессе определенной целенаправленной предметно-преобразующей деятельности; $t_{3}$ - фактически затраченное время, необходимое для достижения поставленных целей в процессе определенной целенаправленной предметно-преобразующей деятельности.

Зависимость, предложенная в формуле, не вступает в противоречие с теоретической сущностью, сформулированной в определении ТК, под которым предложено понимать «реализуемые 
средства и возможности для достижения поставленных целей в процессе определенной целенаправленной предметно-преобразующей деятельности» $[1$, с. 61-70].

Результат, полученный в процессе изучения способов измерения ЧК, позволил объяснить возмож-

\section{ЛИТЕРАТУРА}

1. Антонов А. П. Моделирование понятийного поля с учетом особенностей предметной области исследования капитализации трудового потенциала / А. П. Антонов, В. Я. Сибилева // Сегодня и завтра российской экономики. - 2015. - № 73-74. - С. 61-70.

2. Сибилева В. Я. Подход к описанию процесса капитализация трудового потенциала на основе ГОСТ Р ИСО 704-2010 / В. Я. Сибилева // Гуманитарные основания социального прогресса : Россия и современность : сб. статей Междунар. науч.-практ. конф. Ч. 6. - М. : МГУДТ, 2016. - С. 211-218.

3. Степин B. C. Новая философская энциклопедия : в 4 т. / В. С. Степин, А. А. Гусейнов, Г. Ю. Семигин; Ин-т философии РАН. - М. : Мысль, 2010. - T. IV. - 736 с.

4. Сибилева В. Я. Подход к определению понятия «человеческий капитал» / В. Я. Сибилева, А. П. Антонов // Сборник статей Международной научно-практической конференции. Ч. 1. - Уфа : АЭТЕРНА, 2015. - С. 101-110.

5. Сибилева В. Я. Процесс построения терминологической системы исследования управления капитализацией трудового потенциала работников в организации с учетом особенностей организационной культуры / В. Я. Сибилева, А. П. Антонов // Инновационная наука. 2017. - № 3-1. - С. 211-218.

6. Мясоедова Т. Г. Человеческий капитал и конкурентоспособность предприятия / Т. Г. Мясоедова // Менеджмент в России и за рубежом. - 2005. - № 3. - С. 29-37.

7. Борщевва Н. Л. Развитие методологии управления человеческим капиталом в инновационной экономике : дис. ... д-ра экон. наук : 08.00.05 / Н. Л. Борщева. - М., 2016. -344 c.

8. Каменева К. П. Человеческий капитал аграрного сектора экономики : особенности оценки и направления

Российский государственный университет им. А. Н. Косыгина

Иванова В. Я., аспирант института экономики и менеджмента

E-mail:veramgudt@yandex.ru ность использования интегрального подхода к оценке ТК. Приведенное выше выражение может быть сопряжено с разработанной ранее формулой для измерения ТП [9, с. 57-65] и интегрировано в исследование влияния организационной культуры на процесс капитализации ТП работников в организации.

развития / К. П. Каменева // Вестник ОрелГАУ. - 2009. № 6 (21). - С. 133-137.

9. Иванова В. Я. Подход к оценке трудового потенциала работников в организации / В. Я. Иванова // Государство и бизнес. Экосистема цифровой экономики : материалы XI Междунар.-практ. конф. - СПб., 2019. C. $57-65$.

10. Козлов А. И. Человеческий капитал : становление, сущность, формирование и критерии оценки / А. И. Козлов. - М. : Экономика, 2009. - 95 с.

11. Корицкий А. В. Введение в теорию человеческого капитала / А. В. Корицкий. - Новосибирск : СибУПК, 2000. - 105 c.

12. Курганский C. А. Человеческий капитал : сущность, структура, оценка / С. А. Курганский. - Иркутск : Изд-во БГУЭП, 2003. - 235 с.

13. Бухалков М. И. Управление персоналом : развитие трудового потенциала / М. И. Бухалков. - М. : ИНФРА-М, 2012. - 190 c.

14. Пирожкова Н. И. Оценка стоимости человеческого капитала : монография / Н. И. Пирожкова. - М. : Синергия пресс, 2013. - 127 с.

15. Фития-енц Я. Рентабельность инвестиций в персонал : измерение экономической ценности персонала / Я. Фитц-енц. - М. : Вершина, 2009. - 319 с.

16. Покусаев О. Н. Экономическая оценка человеческого капитала в системе управления человеческими ресурсами компании / О. Н. Покусаев // Этап : экономическая теория, анализ, практика. - 2012. - № 1. C. $138-156$.

17. Корнейчук Б. В. Человеческий капитал во временном измерении / Б. В. Корнейчук. - СПб. : Изд-во СПбГПУ, 2003. - 91 с.

\section{The Kosygin State University of Russia}

Ivonova $V$. . ., Aspirant of the Economics and Management Institute

E-mail:veramgudt@yandex.ru 